\title{
INSERÇÃO DO ASSISTENTE SOCIAL NA POLÍTICA PÚBLICA DE SAÚDE: ABORDAGENS E PERSPECTIVAS
}

\author{
L. C. B. GUERRA*, V. M. AQUINO
}

Instituto Federal de Educação, Ciência e Tecnologia do Rio Grande do Norte lenin.cavalcanti@ifrn.edu.br*

Artigo submetido em 27/10/2016 e aceito em 24/06/2019

DOI: $10.15628 /$ holos.2019.5271

\section{RESUMO}

O presente artigo discute a inserção dos assistentes sociais na política pública de saúde sob a perspectiva da ampliação dos direitos sociais, uma vez que estes profissionais trabalham na prevenção, promoção da saúde e na constante busca por melhorias no sistema público de saúde no tocante ao acesso e ampliação dos direitos à saúde. Posto isso, o objetivo geral: analisar como se deu inserção dos Assistentes Sociais na saúde, do marco do Movimento da Reforma Sanitária até a chegada do Neoliberalismo nos anos de 1990. Na revisão de literatura foram estudados autores que discutem a temática Serviço Social e Saúde como: Bravo (2006), Código de Ética do/a Assistente Social (1993), Minayo (1994) e Parâmetros para atuação de Assistentes Sociais na Política de Saúde (2013), CFESS (1999) além da revisão documental das legislações referentes à saúde, tais como a Constituição Federal da República Federativa do Brasil (1988) e a Lei $n$ ㅇ 8.080. Foi utilizada uma abordagem qualitativa a partir do método das narrativas, o qual irá abordar os principais marcos históricos que personalizam a inserção dos assistentes sociais na saúde, enfatizando principalmente a reforma sanitária, Resolução do CFESS e a chegada do Neoliberalismo. A resolução veio legitimar a atuação desses profissionais no campo da saúde, sendo atualmente a área que mais emprega assistentes sociais no Brasil. Por fim, o estudo constatou que o assistente social tem suas atividades consideradas muitas vezes como irrelevante, tal fato se dá ainda pela maior importância direcionada as práticas curativas, minimizando atividades educativas, de mobilização e comunicação em saúde em conjunto com os diversos profissionais do campo da saúde.

PALAVRAS-CHAVE: Saúde, Serviço Social, Marco legal.

\section{INTEGRATION OF THE SOCIAL WORKER IN PUBLIC HEALTH POLICY: APPROACHES AND PROSPECTS}

\begin{abstract}
The present paper discusses the insertion of Social Assistants in Public Health Policy under a perspective the expansion of social rights, since these profesionals work in prevention, health's promotion and regular improvements in public Health System in relation to access and extension rights health desk. In this way, the general objective is to analyze as the insertion of social assistants in health in the framework of the Health Reform Movement even an arrival of Neoliberalism in 90s. In the literature review have been studied authors who discuss the theme Social and Health Service as: Bravo (2006), Code of Ethics/a Social Worker (1993), Minayo (1994) and Parameters paragraph Practice of Social Workers in Health Policy (2013), besides documentary revision of the laws relating to health such
\end{abstract}

as the Constitution of the Federative Republic of Brazil (1988) and Law 8.080. A qualitative approach was used from the method of the narrative analysis, which will address the major landmarks that customize the inclusion of social workers in health, focusing mainly on health reform, federal council of social assistant resolution and the arrival of Neoliberalism. The resolution legitimized the performance of these professionals in the field of health, being currently the area that employs more social workers in Brazil. Finally, the study found that the social worker has his activities often considered as irrelevant, this fact is given even greater importance to the curative practices, minimizing educational activities, mobilization and communication in health together with the various professionals in the field of health.

KEYWORDS: Health, Social service, Legal framework. 


\section{INTRODUÇÃO}

O Serviço Social, historicamente, tem sido uma profissão destinada a formar profissionais aptos a formular, gerir e executar políticas públicas. A sua institucionalização como profissão na sociedade surgiu, segundo lamamoto (2007), a partir da intervenção do Estado no processo de regulação da vida social atuando na questão social, a qual é o principal objeto de trabalho desse profissional. $\mathrm{O}$ assistente social lida com várias refrações da questão social na vida dos indivíduos e, para isso, trabalha na interface de várias políticas públicas, dentre elas, a de saúde.

A política pública de saúde no Brasil passou por um longo percurso até ser se consolidada como um direito na Constituição Federal de 1988 e na lei 8.080, de 19 de setembro de 1990, conhecida como Lei Orgânica da Saúde. Nesse prisma, esta será analisada nesse trabalho a partir de dois marcos: Movimento da Reforma Sanitária nos anos de 1980 e posteriormente com a chegada do Neoliberalismo nos anos de 1990, levando a saúde para a lógica privatista.

A Reforma sanitária, conforme destaca Bravo (2009), surge a partir da insatisfação adquirida entre o período conservador e transição democrática. Nesse momento, a saúde começa a ser inserida na esfera política e vários sujeitos se unem em prol da universalização do acesso e de melhorias no sistema de saúde. O Estado é visualizado como principal ente responsável pela efetivação desses objetivos. Porém, o movimento começa a perder força na década de 1990, com a implantação da política neoliberal.

No tocante a implantação do Serviço Social, no contexto da Política Pública de Saúde, esta vem atrelada a concepção ampliada de saúde, a qual rompe com o binômio saúde e doença, abrindo novas formas de abordagem para discussões na área da saúde. E válido acrescentar que, com a introdução do Sistema Único de Saúde - SUS no texto constitucional de 1988, a saúde vai ser visualizada como o bem-estar físico, mental e social, ou seja, a saúde não vai estar ligada somente ao fato de não estar doente, pois incidem outros fatores e determinantes sociais sob os condicionantes da saúde do indivíduo como fatores culturais, econômicos e sociais.

É nesse espaço que é introduzido o Serviço Social na saúde que busca a materialização do princípio da universalidade, bem como a ampliação dos direitos dos usuários nos espaços públicos de saúde. A Resolução CFESS N.ㅇ 383, de 29 de março de 1999, é tida como um marco, pois caracteriza o assistente social como profissional de saúde. A resolução legitima a atuação do assistente social na política de saúde, intervindo nos fenômenos socioculturais e econômicos que incidem nos condicionantes da saúde.

Assim, o objetivo geral deste artigo é analisar a inserção dos assistentes sociais na política pública de saúde, do marco do movimento da reforma sanitária até a chegada do neoliberalismo, nos anos de 1990. E como objetivos específicos tem-se: a) fazer um levantamento histórico da saúde, passando pelo movimento da reforma sanitária e chegando a implantação do Sistema Único de Saúde; b) descrever a chegada da corrente neoliberal, nos anos de 1990, fazendo-se uma análise do processo de evolução e retrocesso dos direitos atinentes a saúde nesses períodos; c) identificar como a inserção dos assistentes sociais contribuiu na ampliação do direito à saúde.

Desta feita, este estudo busca contribuir para adoção de novas formas de intervir, bem como amenizar as refrações da questão social no âmbito da saúde, as quais se tornam cada dia 
mais complexas em nossa sociedade. No tocante a relevância da pesquisa para gestão pública os resultados dessa pesquisa poderão contribuir, de forma significativa, para a introdução de novas formas de gerir, planejar, analisar e executar a política de saúde, calcada nos princípios do SUS.

Na sequência, o trabalho se constituirá da seguinte forma: primeiro a introdução a qual irá resumir de forma breve o que será apresentado no decorrer do trabalho desenvolvido, o segundo item irá apresentar os procedimentos metodológicos trabalhados ao longo desse processo, na terceira parte, iniciaremos o referencial teórico abordando o Serviço Social de forma breve até a sua inserção na saúde, logo após será debatido, a política de saúde no marco do movimento sanitário e chegada do neoliberalismo, por último será feita uma análise crítica sobre as contribuições do serviço social na perspectiva de ampliação dos direitos sociais no que concerne ao direito universal a saúde.

\section{REFERENCIAL TEÓRICO}

\subsection{Serviço Social: conceitos e evolução}

A gênese do Serviço Social é encontrada na fase de ascensão do capitalismo, ancorado na fase inicial de acumulação capitalista. Esse período é marcado pela forte exploração da força de trabalho dos operários, os quais viviam em condições sub-humanas. Muitas revoluções ocorreram nesse período, pois os trabalhadores começaram a contestar a situação degradante na qual estavam inseridos e a burguesia visualizava isso como um perigo a ordem social, temiam que as movimentações afetassem o seu poderio.

Para isso, e feita a aliança entre a burguesia, Igreja e Estado objetivando coibir qualquer tipo de manifestação podendo assim continuar a escamotear a desigualdade social. Martinelli (2000, p. 66) contextualiza de forma clara o advento do Serviço Social:

\footnotetext{
A origem do serviço social como profissão tem, pois a marca profunda do capitalismo e do conjunto de variáveis que a eles estão subjacentes - alienação, contradição, antagonismos - pois foi neste vasto caudal que ele foi engendrado e desenvolvido.
}

As condições que determinaram a profissão historicamente, conforme podemos notar veio de mentes capitalistas, as quais criaram a profissão a seu serviço, na medida em que ela seria um instrumento muito relevante de controle social e manutenção do poder burguês.

A expansão das primeiras formas de questão social que podemos denominar ocorridas na Europa dos séculos IX e XX, conforme destaca Pereira (2002) preocuparam os capitalistas; a partir daí começou a ter início as primeiras ações do que viria a ser o serviço social, ações a priori estritamente assistencialistas, que por grande influência da igreja católica eram remetidas a práticas cristãs. A profissão em si era vista como uma vocação divina.

Vale destacar que atualmente o serviço social ainda é visualizado por muitas pessoas por esse viés: caridade e assistencialismo, advindos das protoformas do Serviço Social. Ainda nesse 
contexto, podemos destacar segundo Martinelli (2000), a criação das primeiras escolas de Serviço Social, as quais visavam a profissionalização dos agentes para a prática profissional. A primeira escola surgiu na Inglaterra em 1908 e logo depois foram se expandido em outros países, sendo cada vez mais frequente a busca pelo curso. Higiene, saúde e educação era o lema do serviço naquele período. Os campos de atuação do Assistente Social se ampliaram com bastante rapidez nas instituições públicas e particulares.

É importante salientar que tanto Europa quanto Estados Unidos seguiram embasamentos diferentes no tocante a profissionalização do serviço social. E ambos trouxeram muitos ensinamentos pra prática profissional.

As técnicas e métodos impostados da Europa e Estados Unidos contribuíram com o fazer profissional do Serviço Social por um longo período. Porém, o movimento de reconceituação do Serviço Social ocorrido na América Latina, segundo Netto (1994) rompeu com as práticas conservadoras direcionadas a profissão. A crise do Serviço Tradicional denominada por Netto ocorreu também internacionalmente, foi um fenômeno mundial.

O movimento foi um divisor de águas na história do Serviço Social e caminhou para a construção e materialização do Serviço Social que temos hoje, o qual está emprenhado na luta pela garantia de direitos e na eliminação de todas as formas de desigualdades sociais. Nesse momento histórico, o Serviço Social definitivamente se une a classe trabalhadora e se compromete a defender os direitos dos trabalhadores oprimidos.

Para Oliveira (2003), a ampliação de reflexões que construam o debate a respeito da política pública da assistência para a sua afirmação enquanto política social é uma necessidade atual. No Brasil, o III Congresso Brasileiro de Assistentes Sociais denominado de congresso da virada em 1979, marca esse momento histórico de grande valia para o Serviço Social brasileiro. Neles temos a construção do projeto ético político, a reformulação do Código de Ética Profissional e mudanças nas diretrizes curriculares do Serviço Social todos embasados em um viés progressista. (Behring \& Boschetti, 2007)

No item seguinte, será feita uma abordagem geral do Serviço Social contemporâneo no Brasil.

\subsection{Serviço Social no Brasil e a Política de Saúde}

O Serviço Social é uma profissão de nível superior regulamentada pela Lei 8.662/1993. Para exercer a função de Assistente social é necessário ter cursado uma faculdade de Serviço Social reconhecida pelo MEC e ter registro no Conselho Regional de Serviço Social. É uma profissão que vem historicamente trabalhando no campo das políticas públicas, a mesma tem sua intervenção pautada nas refrações da questão social, seu objeto de trabalho. A profissão é regida por um código de ética, que direciona os valores e princípios a ser seguidos pelos profissionais.

A profissão de Assistente Social possui um projeto ético político pautado na emancipação humana dos cidadãos e igualdade social. O Serviço Social é uma das poucas profissões que possui um projeto profissional coletivo e hegemônico direcionado a construção de uma nova ordem societária. O projeto é materializado nas diretrizes curriculares, nos instrumentos normativos, Lei de regulamentação da profissão e no Código de Ética profissional.

E válido destacar que o surgimento do serviço social como temos hoje foi construído ao longo das décadas. Sendo que inicialmente, conforme apresentam lamamoto e Carvalho (2003) 
ele era usado pelas classes dominantes como instrumento para exercer seus poderes junto aos menos favorecidos.

A institucionalização da profissão ocorre a partir da intervenção estatal na regulação da vida social, a qual vem responder as necessidades sociais advindas das vivências históricas, frutos da produção e reprodução da vida social, conforme destacam lamamoto e Carvalho (2003). Mas, e somente na década de 1930 que a questão social passa a ser introduzida no espaço público de maneira politizada deixando de ser vista como uma "mazela social". Conforme aponta lamamoto $(1998$, p. 27) a questão social é visualizada como:

[...] o conjunto das expressões das desigualdades da sociedade capitalista madura, que tem uma raiz comum: a produção social é cada vez mais coletiva, o trabalho torna-se mais amplamente social, enquanto a apropriação dos seus frutos mantém-se privada, monopolizada por uma parte da sociedade.

A questão social é compreendida como fruto das desigualdades sociais e vem associadas a acumulação de riqueza nas mãos de poucos e a desigualdade na distribuição da riqueza produzida socialmente. Enquanto poucos detêm a maior parte da riqueza do mundo, a grande maioria vive na miséria. Eis aqui a grande contradição da sociedade capitalista que o serviço social procura intervir.

A partir desse contexto, temos a dilatação dos espaços de atuação do assistente social. E o Estado nessa conjuntura passa a ser um dos maiores empregadores de assistentes sociais no Brasil, atendendo de um lado os ideais capitalistas e do outro as demandas sociais, criando uma espécie de equilíbrio.

Os Assistentes Sociais trabalham efetivamente na coordenação, elaboração, análise e implementação das políticas sociais na perspectiva da ampliação e garantia dos direitos sociais. Atuam na interface de várias políticas como saúde, assistência social, habitação, meio ambiente, educação, previdência social e cultura.

No tocante a saúde temos o Sistema Único de Saúde - SUS, como a principal política pública de saúde. Sua criação se deu a partir da Lei 8.080 de 1990. A qual segundo a Constituição Federal: "dispõe sobre as condições para a promoção, proteção e recuperação da saúde, a organização e o funcionamento dos serviços correspondentes" e em seguida com a Lei 8.142 de 1990, está remetese a participação popular e a as transferências intergovernamentais de recursos financeiros da saúde.

A política de saúde no Brasil visa garantir uma qualidade melhor de vida à população usuária do sistema, objetivando diminuir as desigualdades sociais. Porém, é válido salientar que a sua materialização ocorreu através de muitas lutas, movimentos e reivindicações dos segmentos da sociedade que eram a favor do movimento da reforma sanitária, movimento este que tinha como bandeira de luta a: Universalização do acesso a saúde e democratização da gestão.

As bandeiras de luta defendidas pelo movimento da reforma sanitária sem dúvida eclodiram de forma positiva, pois trouxeram a problemática da saúde pública como um problema público que requer a intervenção efetiva do Estado e da sociedade. A universalidade se tornou um dos princípios dos SUS e veio romper justamente com a ideia de que a saúde só podia ser ofertada para quem podia pagar e os demais ficavam a mercê da caridade cristã e filantropia. O princípio trouxe a saúde com universal a qual deve atender a todos cidadãos independentemente de cor, 
raça, origem, etnia e condições econômicas. A saúde como preconiza o SUS deve ser ofertado à população, através de planos, pesquisas e estratégias que possam identificar as principais demandas da população. Para esses fins são criadas as políticas nacionais de saúde direcionadas a cada segmento identificado (Luz, 1991).

É essencial, nesse prisma conhecer a realidade na qual está inserida a saúde, bem como saber quais foram os caminhos tomados ao longo do tempo. Isso possibilitará formas mais fáceis e eficazes de conhecer o público alvo da política e identificar, sobretudo os seus pontos fortes e limites para efetivação da política.

\section{METODOLOGIA}

O percurso metodológico adotado nesse trabalho vai ser dado a partir da utilização de pesquisa bibliográfica com embasamento teórico em alguns autores como: Minayo (1994), Martinelli (2000), lamamoto (2003), Bravo (2006), CFESS (1999) dentre outros, além de pesquisa documental a partir da análise de documentos do Ministério da Saúde como: legislações referentes à saúde, tais como a Constituição Federal da República Federativa do Brasil (1988), a Lei no 8.080 (1990) e outras que norteiam as intervenções dos profissionais de Serviço Social na saúde.

O seguinte levantamento bibliográfico subsidiará a pesquisa supracitada, possibilitando uma análise crítica do objeto de estudo frente à realidade o qual aborda a inserção do assistente social na política pública de saúde. Para isso, utilizaremos a abordagem qualitativa que segundo Marconi e Lakatos (2010) estudam o universo de crenças, valores, atitudes e significados do ser humano, na medida em que estes não devem ser suprimidos a materialização de uma variável. 0 uso dessa abordagem no trabalho nos possibilitará uma maior aproximação com o universo de conceitos e valores.

A análise dos dados será realizada pelo método das narrativas. Conforme apontam Barzelay e Cortázar-Velarde (2004), o método das narrativas representa os conjuntos de ações ou ocorrências organizadas em função de seu significado no âmbito de uma experiência apreendida em sua totalidade. Nessa perspectiva, ela irá descrever os principais marcos históricos que personalizam a inserção dos assistentes sociais na saúde, enfatizando principalmente a reforma sanitária, Resolução do CFESS e a chegada do Neoliberalismo.

Embasado no método das narrativas, o trabalho em questão abordará a seguinte estrutura:

\section{Quadro 1: Marcos Temporais}

EVENTOS ANTERIORES:

- Criação das Caixas de Aposentadoria e Pensões (CAPs); Lei Elói Chaves - 1923

- A construção do Projeto de Reforma Sanitária - 1980

- Realização da 8a Conferência Nacional de Saúde - 1986

- Constituição Federal - 1988

- Lei 8.080 - 1990

\section{EVENTO CENTRAL:}

- Resolução CFESS N. 383/99 de 29/03/1999 - Inserção do Assistente Social na Saúde

\section{EVENTOS POSTERIORES:}

- Implantação das políticas neoliberais no Brasil - 1990

Fonte: Elaborado pelos autores baseado em Barzelay e Cortázar-Velarde (2004). 
Barzelay e Cortazar-Velarde (2004) afirmam que o conjunto de eventos mais diretamente ligados ao processo em análise é chamado de episódio ou evento central. Esse conjunto de eventos está dentro de outros circunvizinhos, incluindo-se os prévios, contemporâneos, relacionados (os que coincidem com o episódio e são afetados por esse) e posteriores (aqueles que ocorrem condicionados pelo evento central do episódio).

Conforme podemos visualizar na figura o Evento Central destacado para as análises desse estudo é a Resolução CFESS N.o 383/99 de 29/03/1999 que dispões sobre a Inserção do Assistente Social na Saúde. A resolução vem legitimar e reconhecer o assistente social como um profissional habilitado para trabalhar na área da saúde.

\section{ANÁLISE DOS RESULTADOS}

\subsection{Eventos anteriores}

A representação da medicina previdenciária foi marcada pela criação das Caixas de Aposentadoria e Pensões (CAPS), estas beneficiavam apenas algumas categorias profissionais e eram mantidas pela União em parceria com empresas e empregadores. Como benefícios eram conforme Bravo (2006, p.90) os benefícios eram proporcionais às contribuições e foram previstos: "assistência médico-curativa e fornecimento de medicamentos; aposentadoria por tempo de serviço, velhice e invalidez; pensão para os dependentes e auxílio-funeral." É válido destacar que na Lei Elói Chaves, Decreto ${ }^{\circ}$ 4.682, de 24 de janeiro 1923, criada pelo deputado de mesmo nome, garantia auxílio financeiro a poucos beneficiários.

Conforme Bravo (2009), os trabalhadores do setor urbano associados ao complexo exportador, foram pioneiros na luta pelas CAPs em suas empresas. Sendo os ferroviários em 1923 e os marítimos em 1926. As outras categorias, só conseguiram esse feito após 1930, período em que se inicia o processo de industrialização no país - momento marcado por grandes transições sociais, econômicas, políticas e culturais.

No tocante a intervenção do Estado na saúde, esta ocorre no ano de 1930, período marcado, segundo Bravo (2009), por grandes mudanças políticas e econômicas, as quais desencadearam o processo de industrialização no país bem como o surgimento das primeiras políticas sociais seguida de uma nova configuração de Estado.

A conjuntura de 1930 favoreceu a criação de políticas que vieram responder as sequelas da questão social. A política de saúde, nosso objeto de estudo nesse trabalho, conforme destaca Bravo (2009) foi formulada em dois subsetores: saúde pública e medicina previdenciária. A saúde pública foi até meados dos anos 60 sendo destinada a pessoas da zona urbana e rural, a mesma ofertava condições mínimas de saúde a esse segmento. No tocante a medicina previdenciária, está foi exaltada em 1966.

A consolidação da política de saúde nessa conjuntura conforme destaca Neto (1994) ocorreu no período de 1945 a 1950. Especialmente em 1948 com a criação do Plano Salte, o qual inseria a saúde como uma pauta dentro da agenda do governo.

No período de 1945 a 1964 os gastos com saúde foram mais significativos, percebendo-se uma melhoria nas condições sanitárias da população. Já na Ditadura Militar, as sequelas da questão 
social foram agravadas e a medicina previdenciária se expandiu. A medicina curativa, individual e assistencialista ganhou ênfase.

A Ditadura Militar trouxe um período de grande descontentamento para a população em geral, assim retratado por Luz (1991, p. 15)

No final da década de 70 e início de 80 , sindicatos e partidos iniciaram uma fase de agitação, questionando a saúde e as políticas de saúde no Brasil. Acadêmicos, cientistas e "tecnocratas progressistas" debatiam em seminários e congressos as epidemias, as endemias e a degradação da qualidade de vida da população. A discussão tomou força com os movimentos populares (associação de moradores, de mulheres, sindicatos, igreja e partidos políticos), que passaram a exigir soluções para os problemas da saúde criados pelo regime autoritário.

Na saúde podemos relatar como destaque o movimento da Reforma Sanitária, o qual de acordo com Bravo (2009) foi expresso em uma grande luta, no qual vários sujeitos sociais se unirão em prol da construção do projeto de Reforma Sanitária, um marco de conquista para a saúde brasileira dando legitimidade a saúde como um direito de todos, prevista na Constituição Federal de 1988.

Outro evento importante foi o Movimento de Reforma Sanitária, que deixou de ser uma questão dos técnicos da área e se tornou uma questão pública. A Reforma, segundo Scliar (1987), baseou-se na Revolução Sanitária Italiana, um dos espelhos das necessidades daquele país, e surgia na época da redemocratização brasileira. No entanto, a participação do Serviço Social nessa luta foi indireta, uma vez que nesse período o serviço social estava passando por um processo de reconceituação, o qual moldava a nova face do Serviço Social brasileiro.

Um dos eventos mais importantes deu-se em 1988, com a promulgação da Constituição Federal, em 1988. Neste momento a política de saúde ultrapassou a análise setorial, abrangendo a saúde em sua totalidade, e propôs-se a criação do Sistema Único de Saúde - tendo como base as propostas advindas da Reforma Sanitária. Almejava-se, então, que a concepção de saúde mudasse, não sendo somente visualizada pelo método curativo, sendo considerada apenas como ausência de doença, mas que está adquirisse um conceito mais amplo, incluindo, por exemplo, saneamento básico, moradia, alimentação, etc.

A saúde ficou definida na Carta Magna como um direito universal, como podemos ver em um trecho do artigo 196 da CF/88:

\footnotetext{
A saúde é direito de todos e dever do Estado, garantido mediante políticas sociais e econômicas que visem à redução do risco de doença e de outros agravos e ao acesso universal e igualitário as ações e serviços para sua promoção, proteção e recuperação (Constituição Federal, 1988).
}

Ao enfatizar o acesso à saúde deve ser de todos, sem distinção de gênero, sexo, etnia, cor ou classe social, sendo ela um dever do Estado, a Constituição Federal valoriza fortemente da política de saúde, além de propiciar as bases para a regulamentação da Lei 8.080/1990, também conhecida como Lei Orgânica da Saúde - SUS, a qual rege toda a política de saúde no país, englobando-se todas as ações e serviços de saúde, executados isolada ou conjuntamente, em caráter permanente ou eventual, por pessoas naturais ou jurídicas de direito Público ou privado. 
A lei 8.080/1990 caracteriza o que é o SUS, dispondo, basicamente, "sobre as condições para a promoção, proteção e recuperação da saúde, a organização e funcionamento dos serviços correspondentes [...]", sendo composto também pela lei 8.142/1990, que dispõe, basicamente, sobre "a participação da comunidade na gestão do SUS e sobre as transferências intergovernamentais de recursos [...]".

O SUS (1990) é composto por princípios e/ou diretrizes como: universalidade, integralidade; intersetorialidade; descentralização; regionalização e hierarquização; garantia do financiamento Estatal e participação social. A criação desse modelo de saúde centrado na promoção, prevenção e recuperação da saúde abriu espaço pra vários segmentos profissionais, entre eles podemos destacar a chegada dos assistentes sociais na política pública de saúde. Estes contribuem efetivamente para ampliação dos direitos sociais nessa política.

Os eventos descritos nesta seção foram fundamentais para o desenvolvimento de uma estrutura que conferiu maior importância ao profissional do Serviço Social, afirmando, apesar de seu caráter transversal, a sua classificação como profissional da saúde.

\subsection{Evento central}

4.2.1 Resolução CFESS N.o 383/99 de 29/03/1999 - Inserção do Assistente Social na Saúde

A inserção do Serviço Social na saúde foi garantida por meio da regulamentação da profissão nessa área, através da Resolução 338/1999 do Conselho Federal de Serviço Social CFESS. A qual reconhece o profissional de Serviço Social como profissional de saúde.

A resolução sem dúvida veio legitimar a atuação desses profissionais no campo da saúde, sendo atualmente a área que mais emprega assistentes sociais no Brasil. A resolução citada foi originada através de várias deliberações do conjunto CFESS/CRESS, os quais têm poder legal para criar regimentos e normativas para a categoria de assistentes sociais.

A aprovação da presente Resolução foi executada pelo Plenário do Conselho Federal de Serviço Social em reunião ordinária realizada em 27 e 28 de março de 1999 e assinada pela Presidente do CFESS, Valdete de Barros Martins.

Os pontos principais da resolução versam sobre: a identificação do Assistente Social como legitimo profissional da área da saúde e sobre sua atuação no âmbito das várias políticas sociais, o que garante que o assistente social não é exclusivo nesse campo.

A Resolução parte de três bases: a $\mathrm{CF} / 88$, que "estabelece a saúde como um direito de todos e dever do Estado, devendo ser garantido mediante políticas sociais e econômicas que visem a redução do risco de doenças e de outros agravos", mas que também cita o "acesso universal e igualitário às ações e serviços para a promoção, proteção e recuperação da saúde"; as conclusões da 8a Conferência Nacional de Saúde, que construiu um novo conceito de saúde a partir da ampliação da "compreensão da relação saúde-doença, como decorrência das condições de vida e de trabalho"; e também da 10a Conferência Nacional de Saúde, que "reafirmou a necessidade de consolidar o Sistema Único de Saúde, com todos os seus princípios e objetivos. (CFESS, 1999)

O Art. 1 ㅇ da Resolução CFESS N. 383/99 estabelece: 


\begin{abstract}
Caracterizar o Assistente Social como profissional de saúde. Na medida em que o assistente social faz sua intervenção junto aos fenômenos sócios-culturais e econômicos que interferem nos determinantes do processo saúde/doença. Além disso, participam efetivamente promoção e proteção da saúde, levando a frente os princípios e diretrizes do SUS.
\end{abstract}

No Art. 2ㅇ - O assistente social atua no âmbito das políticas sociais e, nesta medida, não é um profissional exclusivamente da área da saúde, podendo estar inserido em outras áreas, dependendo do local onde atua e da natureza de suas funções.

Esse artigo destaca o quesito do profissional que pode estar inserido na política de saúde, mas faz uma ressalva que este não é exclusivo da saúde, como exemplo, o enfermeiro, médico e etc., valorizando a atuação transversal do profissional uma vez que o Assistente Social antes de tudo deve realizar sua intervenção em uma perspectiva que considere a totalidade, focada na identificação dos determinantes sociais, econômicos e culturais das desigualdades sociais, propondo sempre uma análise crítica da realidade.

As principais atividades desenvolvidas pelo assistente social são as atividades socioeducativas. As quais são de grande valia para o enfrentamento da questão social na saúde. Além desses suportes legais, podemos inserir alguns princípios Código de Ética do Assistente Social como o da equidade e da justiça social e universalidade de acesso aos programas e políticas sociais, estes contribuem para o reconhecimento da profissão na saúde.

Essas informações podem ser visualizadas no quinto princípio do Código de Ética do Assistente Social que dispõe sobre: "Posicionamento em favor da equidade e justiça social, que assegure universalidade de acesso aos bens e serviços relativos aos programas e políticas sociais, bem como sua gestão democrática". (CFESS, 1993)

Nesse eixo ainda podemos citar um documento de grande valia que regulamenta o fazer profissional na política de saúde que é os Parâmetros para a Atuação de Assistentes Sociais na Saúde (2009), neles podemos citar algumas competências e atribuições que são dirigidas a esses profissionais na saúde como: realizar estudos socioeconômicos; trabalhos com indivíduos, famílias e comunidades; notificações às autoridades competentes, em casos de suspeita ou comprovação de violência, potencialização da participação da sociedade no controle social da política de saúde, dentre outras atribuições.

Diante disso, podemos constatar que a inserção desse profissional na política de saúde veio atender as necessidades mediatas e imediatas da população advindas da questão social. Conforme destaca Costa (2006) o assistente social é o profissional responsável pela acolhida, pois inicia o primeiro atendimento com os usuários pra depois direcioná-los ao atendimento especializado. A primeira necessidade está em identificar os usuários que precisam de um atendimento mais profundo e depois o segundo passo do assistente social e mobilizar a família pra contribuir no tratamento.

E válido enfatizar que o assistente social na política de saúde trabalha de forma interdisciplinar realizando sua intervenção em conjunto com diversos outros profissionais entre eles: enfermeiros, médicos e psicólogos. Essa junção de saberes só tende a enriquecer o trabalho no âmbito do SUS. 
Contudo, a busca de fato pela intervenção do Assistente Social é solicitada essencialmente pra preencher as lacunas deixadas pela não implementação da Lei do SUS. Reafirmando essa ideia ainda de acordo com Costa (2006), o assistente social surge para desburocratizar as ações entre os níveis de prestação de serviço e no tocante a política de saúde e demais políticas sociais.

Para isso, o trabalho desse profissional deve ser pautado em uma análise crítica, a qual objetiva a ampliação e reconhecimento dos direitos sociais conquistados pela população. Neste ponto, a resolução amplia o papel do assistente social ao considerar

\footnotetext{
...que as ações de saúde devem se dar na perspectiva interdisciplinar a fim de garantir a atenção a todas as necessidades da população usuária na mediação entre seus interesses e a prestação de serviços. Considerando que atribui-se ao assistente social, enquanto profissional de saúde, a intervenção junto aos fenômenos socioculturais e econômicos que reduzam a eficácia dos programas de prestação de serviços nos níveis de promoção, proteção e/ou recuperação da saúde; Considerando que o Assistente Social, em sua prática profissional contribui para o atendimento das demandas imediatas da população, além de facilitar o seu acesso às informações e ações educativas para que a saúde possa ser percebida como produto das condições gerais de vida e da dinâmica das relações sociais, econômicas e políticas do País. (CFESS, 1999)
}

A resolução afetou diretamente os usuários da política de saúde de modo que estes devem ter seus direitos desburocratizados e garantidos tal qual manda o texto da Lei. Procura-se nessa medida resgatar os princípios defendidos na reforma sanitária. Princípios estes, hoje corroídos pelas políticas neoliberais presentes na política de saúde.

Nesse prisma, podemos visualizar o profissional de Serviço Social digno de uma total legitimidade para atuar frente às questões sociais na saúde, porém atualmente vem sendo mais requisitado em decorrência da desconstrução dos direitos sociais conquistados no período da Reforma Sanitária. Esse fato corre a partir da implantação das políticas neoliberais, as quais serão detalhadas no próximo item.

Podemos ainda inserir que o assistente social devido ao modelo médico hegemônico, apresentando por Bravo (2006) tem suas atividades consideradas muitas vezes como irrelevante, tal fato se dá ainda a centralidade direcionada as práticas curativas, sendo que estas escamoteiam a importância do trabalho pautado na prevenção e promoção da saúde como: atividades educativas, de mobilização e comunicação em saúde em conjunto com os diversos profissionais do campo da saúde.

A desconstrução desse modelo é, no entanto, um desafio que precisa ser superado, visando-se práticas mais humanizadas na saúde.

\subsection{Eventos posteriores}

O neoliberalismo é uma doutrina formulada por economistas alemães, franceses e norteamericanos. A mesma conforme destaca Coelho (2012) tinha a intenção de desregular o mercado, pois esse processo expandiria o avanço capitalista.

No tocante as políticas sociais adquiridas no Estado de bem estar social, essas seriam reduzidas, pois eram vistas como não rentáveis ao sistema vigente e pra isso era necessário diminuir custos. Nessa perspectiva podemos ver como se configuraria o neoliberalismo em vários países, ainda de acordo com Coelho (2012, p. 99): 
A agenda neoliberal - colocada em prática, primeiro na Inglaterra e nos Estados Unidos, e posteriormente e diversos países do mundo, inclusive sob governos socialistas, como o de Felipe González, na Espanha (1982-1996) - seria baseada no tripé desregulamentação, privatizações e abertura dos mercados.

No Brasil podemos ver o início desse sistema na década de 1990, no qual, conforme Bravo (2009) ocorre um redirecionamento do papel do Estado, impulsionado pela política de ajuste neoliberal. Essa política desviou as funções básicas do Estado como principal ente responsável pelo desenvolvimento econômico e social, sendo as suas atividades direcionadas para o mercado.

Essa ideologia adotada trouxe muitas perdas das conquistas adquiridas no período do Movimento da Reforma Sanitária em 1980. Com a introdução da mercantilização da saúde, fragilização dos vínculos empregatícios dos funcionários desse campo, terceirização das ações de saúde e entre outros. Esses pontos citados vieram romper com o princípio da universalização da saúde e integralidade das ações e serviços conquistados no período da reforma.

Ainda segundo Bravo (2009, p. 100), "a afirmação da hegemonia neoliberal no Brasil tem sido responsável pela redução dos direitos sociais e trabalhistas, desemprego estrutural, precarização do trabalho, desmonte da previdência pública, sucateamento da saúde e educação."

O neoliberalismo trouxe um grande impacto na área social ficando o Estado conforme CFESS (2010) com a atribuição de garantir o mínimo aos usuários que não tem condições financeiras de pagar pelo serviço, no entanto, as demais atividades e serviços mais complexos ficaram associados à lógica do mercado, nos quais permitiam somente ter acesso quem podia pagar pelo serviço.

Essa perspectiva adotada é visivelmente excludente, pois a maioria dos usuários da saúde é integrante de classe menos desfavorecida economicamente. Desse modo, seu direito de acesso a saúde é suprimido.

Além disso, podemos ver a supervalorização a privatização da saúde e inserção do mercado nas atividades relacionadas a saúde, tal fato contrária o que é posto na Constituição, pois a saúde privada deve ser inserida no SUS apenas como caráter completar, sendo que na verdade isso não ocorre na prática.

Nesse sentido, podemos ver claramente que na nossa sociedade dois projetos vivem em constante disputa: o da reforma sanitária construído em 1980 e o projeto de saúde ligado a lógica neoliberal em 1990. A função do Estado neoliberal é garantir o mínimo aos que não podem pagar pelo serviço e privatizar os serviços para aqueles que possuem poder de compra.

A universalidade do direito a saúde fica limitada com o uso de práticas individualistas e fragmentadas. Como aponta CFESS (2010, p. 20):

\footnotetext{
O Sistema Único de Saúde (SUS) completou vinte anos de existência e, não obstante ter conseguido algumas inovações, o SUS real está longe do SUS constitucional. Há uma enorme distância entre a proposta do movimento sanitário e a prática do sistema público de saúde vigente. O SUS foi se consolidando como espaço destinado aos que não têm acesso aos subsistemas privados, como parte de um sistema segmentado. A proposição inscrita na Constituição de 1988 de um sistema público universal não se efetivou, apesar de alguns avanços, como o acesso de camadas da população que antes não tinham direito.
} 
Os assistentes sociais aparecem nesse cenário como principais agentes responsáveis pela devolução dos direitos sociais negados nesse contexto. Tal fato, só vem reafirmar a importância da prática desses profissionais na política pública de saúde. A qual vem tendo os seus direitos derruídos pela perversa lógica neoliberal, a qual reforça a ideia do Estado mínimo de direitos.

O trabalho deve ser voltado principalmente pra o fortalecimento do Sistema único de Saúde de modo que este atenda as reais necessidades da população.

\section{CONSIDERAÇÕES FINAIS}

A política pública de saúde no Brasil surgiu através de muitas lutas, as quais culminaram na criação da Lei Orgânica da Saúde, marco legal que deu espaço para a inserção dos profissionais de Serviço Social, tendo como base as necessidades dos diferentes segmentos da classe trabalhadora, objetivando garantir o direito universal à saúde inscrito na Constituição Federal de 1988.

A inserção da categoria dos assistentes sociais foi legitimada pela resolução 338/1999 do Conselho Federal de Serviço Social - CFESS que reconhece o profissional de Serviço Social como profissional de saúde. A presente resolução traz em seu artigo primeiro a definição do assistente social conforme citado anteriormente, como legitimo profissional capacitado a atuar no âmbito da saúde, o mesmo trabalha na promoção e proteção da saúde amparado nos princípios e diretrizes do SUS.

O objetivo geral da pesquisa foi atingido na medida em que pudemos analisar como se deu o processo de inserção dos assistentes sociais na saúde desde o marco do Movimento da Reforma Sanitária até a chegada das políticas neoliberais na década de 1990. O detalhamento desses aspectos ocorreu através da utilização do método das narrativas, o qual permitiu seguir uma linha cronológica destacando os principais eventos que contribuíram para a concretização do evento central.

Por fim, o estudo buscou destacar a relevância da atuação do Assistente Social no campo da saúde pública, apesar das diversas dificuldades que este profissional enfrenta para exercer o seu fazer profissional coerente com os princípios e diretrizes adotados pelo SUS. Compreender o Serviço Social articulado a outros setores na defesa do aprofundamento do Sistema Único de Saúde visando à ampliação do direito a saúde como universal e que deve ser estendido a todos foi também um dos objetivos do estudo desenvolvido nesse trabalho.

No tocante as perspectivas para estudos futuros, destacamos a intenção de dar uma maior visibilidade a esses profissionais, muitas vezes tidos como invisíveis, os quais atuam efetivamente na garantia de direitos e ampliação dos direitos sociais.

\section{REFERÊNCIAS}

Arora, M.L., Barth, E., Umphres, M.B. (1985) Technology evaluation of sequencing batch reactors. Journal Water Pollution Control Federation, v.57, n.8, p. 867-875, ago.

Behring, E.R.; Boschetti, I. (2004) Política Social: fundamentos e história. 3. ed. São Paulo: Cortez. 
Barzelay, M.; Cortázar-Velarde, J. C. (2004) Una guía practica para la elaboración de estudios de caso sobre buenas practicas en gerencia social. Washington: Instituto Interamericano para el Desarrollo Social (INDES)/Banco Interamericano de Desarrollo.

Brasil. Constituição (1990). Constituição da República Federativa do Brasil: promulgada em 5 de outubro de 1988. Organização do texto por Juarez de Oliveira. 4. ed. São Paulo: Saraiva.

CFESS. Conselhos Regionais de Serviço Social. (2013) Parâmetros para a Atuação de Assistentes Sociais na Saúde. Grupo de trabalho serviço social na saúde. Brasília.

Coelho, R. C. (2012) Estado, Governo e Mercado. 2. ed. Florianópolis. Florianópolis: UFSC.

Conselho Federal De Serviço Social. (1993) Código de Ética Profissional do (a) Assistente Social. Lei no $8662 / 93$.

Datar, M.T.; B., D.S. (1998) Effects of environmental factors on nitrification during aerobic digestion of activated sludge. Journal of the Institution of Engineering, v.68, n.2, p.29-35, Fev.

lamamoto, M. V. (1998) O Serviço Social na Contemporaneidade: trabalho e formação profissional. 4. ed. São Paulo: Cortez.

Datar, M.T.; Carvalho, R. (2003) Relações Sociais e Serviço Social no Brasil: Esboço de uma interpretação histórico- metodológica. 15. Ed. São Paulo, Cortez.

Luz, M. T. (1991) Notas sobre as políticas de saúde no Brasil de "transição democrática" - anos 80. PHYSIS - Revista de Saúde Coletiva, São Paulo, v.1, n.1.

Marconi, M. A.; Lakatos, E. M. (2010) Fundamentos de metodologia científica. 7. ed. São Paulo: Atlas.

Minayo, M. C. S. (1994) Violência social sob a perspectiva da saúde pública. Cad. Saúde Pública, Rio de Janeiro, v. 10, supl. 1, p. S7-S18. Disponível em $<$ http://www.scielo.br/scielo.php?script=sci_arttext\&pid=S0102311X1994000500002\&lng=en\&nrm=iso>. Acesso em 16 fev. 2018.

Neto, J. P. (1994) Ditadura e Serviço Social: uma Análise do Serviço Social no Brasil pós -64. 2.ed. São Paulo.

Oliveira, í. M. (2003) Política Social, Assistência Social e Cidadania: algumas aproximações acerca do seu significado na realidade brasileira. Revista Desafios Sociais, Ano I, № 2, Natal-RN: Editora da UFRN, Setembro.

PEREIRA, P. A. (2002) Política de Assistência Social no Brasil: avanços e retrocessos. In: Cadernos Ceam. Brasilia: UNB, CEAM, NEPPOS, $n^{\circ} 11$.

SCLIAR, M. (1987) Do mágico ao social: a trajetória da Saúde Pública. Porto Alegre: L\&PM Editores. 